\title{
INDICADORES DO PROCESSO DE DESERTIFICAÇÃO: A ANÁLISE MULTITEMPORAL DA BIOMASSA VERDE NO MUNICÍPIO DE CANUDOS, ESTADO DA BAHIA.
}

\author{
João Gabriel de Carvalho Vieira ${ }^{1}$; Jocimara Souza Britto Lobão²; Diego Oliveira Costa ${ }^{3}$ \\ 1. Bolsista PIBIC/CNPq, Graduando em Lic. Geografia, Universidade Estadual de Feira de Santana, e-mail: \\ igcgeo@gmail.com \\ 2. Orientador, Departamento de Ciências Humanas e Filosofia, Universidade Estadual de Feira de Santana, e-mail: \\ juci.lobao@gmail.com \\ 3. Participante do projeto, Departamento de Ciências Humanas e Filosofia, Universidade Estadual de Feira de Santana, e- \\ mail: costapdiego@gmail.com
}

PALAVRAS-CHAVE: Desertificação; Indicador; Temperatura da superfície.

\section{INTRODUÇÃO}

As discussões acerca das questões ambientais ganham maior repercussão em meados do século XX, em função da constatação de crises ambientais vivenciadas em escalas globais, regionais e locais, decorrentes da exploração social do patrimônio ambiental. O processo denominado de Desertificação enquadra-se como um dos grandes problemas ambientais, vivenciado em regiões de "terras secas" que apresentam irregularidades climáticas e intensa pressão antrópica em suas abrangências. Tal processo é definido como "a degradação das terras nas zonas áridas, semiáridas e sub-úmidas secas, resultante de vários fatores, incluindo as variações climáticas e as atividades humanas" (ONU, 1997; AB'SABER, 1977; VASCONCELO SOBRINHO, 1971; BRASIL, 2004; OLIVEIRA JUNIOR, 2014; LOBÃO, 2013). No município de Canudos, localizado na região semiárida da Bahia, o processo de degradação ambiental encontra-se em estágio avançado, sendo este resultado da ação humana sobre seu ecossistema frágil e seco, caracterizando áreas que supostamente esteja passando pelo processo de desertificação. Este trabalho analisou o comportamento da biomassa verde como indicador do processo de desertificação, com a utilização de imagens geradas pela combinação espectral expressa pela fórmula do Índice de vegetação normal diferenciada (NDVI) nos anos de 2001, 2014 e 2016. Levantando dados a partir do mapeamento dos níveis da biomassa, identificação da mudança na densidade, comportamento sazonal da vegetação, caracterização de áreas com diferentes concentrações e evidenciação da vulnerabilidade ambiental ocasionada pela exposição dos solos.

\section{MATERIAL E MÉTODOS}

Para realização do cálculo do Normalized Difference Vegetation Index - NDVI, foi utilizado uma imagem do satélite Landsat 5, sensor TM para o ano de 2001 e Landsat, 8 para os anos de 2014 e 2016, com o sensor OLI, ambas com resoluções espaciais de 30m.

Quadro 01 - Dados das imagens Landsat 5 e Landsat 8

\begin{tabular}{|c|c|c|c|}
\hline Cena & Orbita/ponto & Data & Período \\
\hline Bandas 3 e 4 & $216 / 67$ & $2001-05-06$ & Chuvoso \\
\hline Bandas 3 e 4 & $216 / 67$ & $2001-09-27$ & Seco \\
\hline Bandas 4 e 5 & $216 / 67$ & $2014-05-10$ & Chuvoso \\
\hline Bandas 4 e 5 & $216 / 67$ & $2016-10-06$ & Seco \\
\hline
\end{tabular}

Elaboração: João Gabriel de Carvalho Vieira, 2017. 
O NDVI é calculado pela diferença entre as bandas do Infra Vermelho Próximo e do Vermelho, normalizada pela soma das mesmas bandas:

$$
\mathrm{NDVI}=\frac{I V P-V}{I V P+V}
$$

Sendo: NDVI - Valor do Índice de Vegetação da Diferença Normalizada;

IVP - Valor da refletância na faixa do infravermelho próximo;

V- Valor da refletância na faixa do vermelho.

O resultado do cálculo do NDVI é expresso através do espectro que varia de -1 à 1 , que representa a mínima e a máxima quantidade de biomassa verde respectivamente. Estes valores são expressos por meio de um espectro de cores que variou do verde (maior densidade de biomassa verde) ao vermelho (menor densidade de biomassa verde), distribuída em classes.

\section{RESULTADOS E/OU DISCUSSÃO}
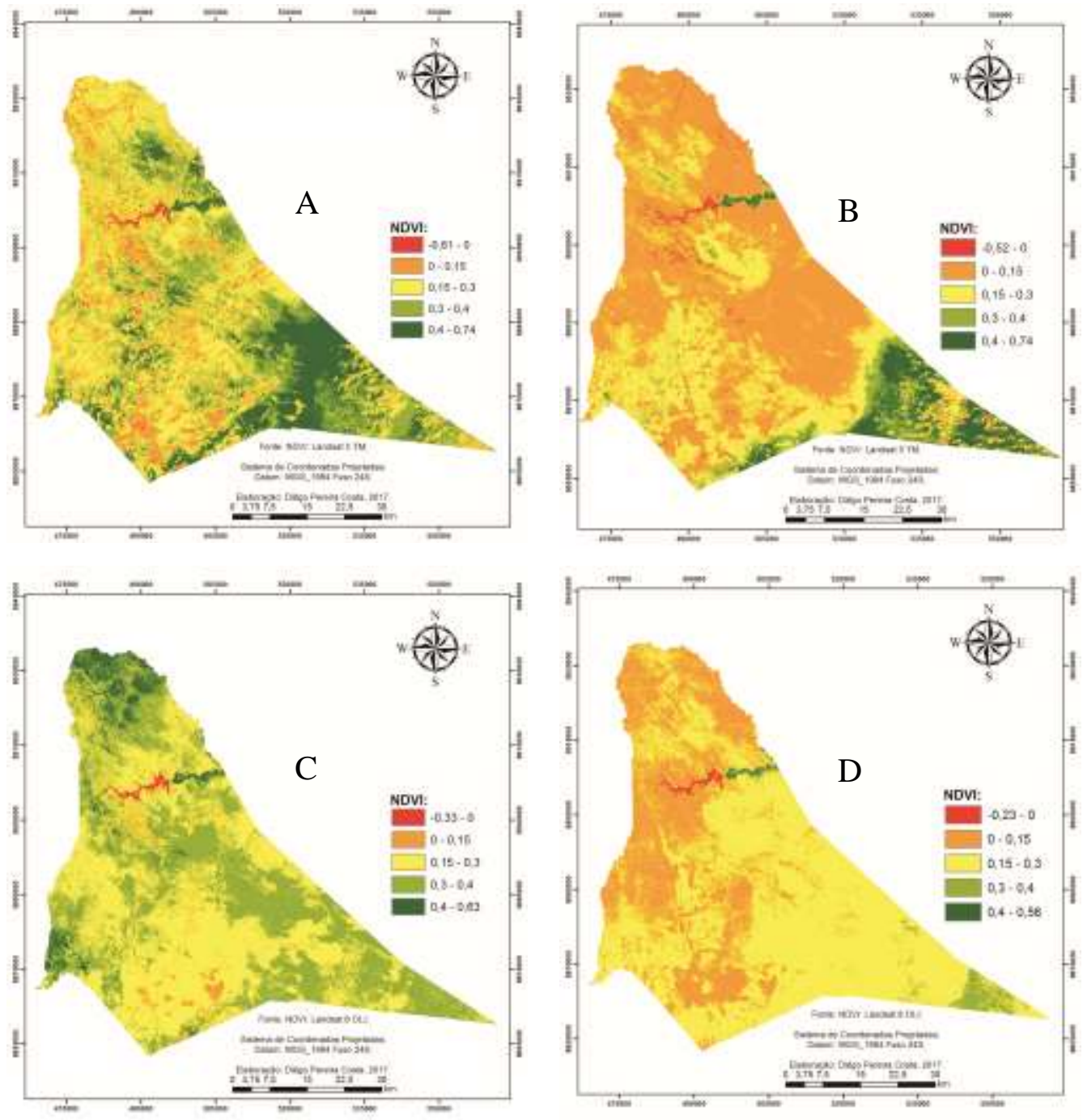

Figura 01 - Imagens do NDVI no município de Canudos-BA. A - NDVI, Maio 2001; B - NDVI, setembro 2001; C - NDVI,

Maio 2014; D - NDVI, setembro 2016.

As características, intervalos e comportamento espectral das classes em NDVI, são apontados pelo quadro 02 e quantificação das classes na tabela 01 . 
Quadro 02 - Definição das classes em NDVI

\begin{tabular}{|l|l|c|c|}
\hline $\begin{array}{l}\text { Classe } \\
\text { NDVI }\end{array}$ & \multicolumn{1}{|c|}{ Característica das classes } & Cor & $\begin{array}{c}\text { Intervalos de } \\
\text { classes }\end{array}$ \\
\hline 01 & Corpos d'agua e sobra de nuvens & & 0 \\
\hline 02 & Densidade de biomassa rarefeita & & 0,15 \\
\hline 03 & Densidade de biomassa mediana & & 0,3 \\
\hline 04 & $\begin{array}{l}\text { Densidade de biomassa } \\
\text { concentrada }\end{array}$ & & 0,4 \\
\hline 05 & Alta densidade de biomassa & & 0,55 \\
\hline
\end{tabular}

Elaboração: João Gabriel de Carvalho Vieira, 2017

Tabela 01 - Quantificação das classes em NDVI

\begin{tabular}{lcccccccc}
\hline \multirow{3}{*}{ Classes } & \multicolumn{4}{c}{2001} & \multicolumn{4}{c}{2014} \\
\multicolumn{2}{c}{2016} \\
& \multicolumn{2}{c}{ CHUVOSO } & \multicolumn{2}{c}{ SECO } & \multicolumn{2}{c}{ CHUVOSO } & \multicolumn{2}{c}{ SECO } \\
& $\%$ & AREA & $\%$ & AREA & $\%$ & AREA & $\%$ & AREA \\
\hline 01 & 1,0 & 32,5 & 1,2 & 39,9 & 0,48 & 15,4 & 0,52 & 17,02 \\
02 & 15,5 & 498,4 & 31 & 1002,6 & 2,5 & 82,5 & 32,8 & 1053,9 \\
03 & 41,7 & 1338,8 & 55 & 1754,7 & 49,8 & 1600 & 64 & 2058,4 \\
04 & 26 & 836,5 & 6,8 & 221,3 & 41,8 & 1344,3 & 2,3 & 74,1 \\
05 & 17,8 & 504,7 & 6,0 & 192,7 & 5,3 & 168,9 & 0,24 & 7,9 \\
\hline
\end{tabular}

Elaboração: João Gabriel de Carvalho Vieira, 2017

A imagem 1 (figura 01) é referente ao cálculo de NDVI em maio de 2001, período chuvoso, onde a vegetação e consequentemente a biomassa verde refletirá com maior intensidade devido a presença de água, que possibilita alterações na forma e estruturas das plantas que irão compor a biomassa verde na área de estudo. No município, as regiões que concentram as maiores densidades de biomassa estão variando entre as classes $4(0,3$ a 0,4$)$ que possui $26 \%$ da área total e $5(0,4$ a 0,74$)$ com aproximadamente $17,8 \%$, localizadas na porção sudeste e norte. Já a predominância das menores concentrações são representadas pelas classes $3(0$ a 0,15$)$, com $41,7 \%$ e $2(0,15$ a 0,3$)$ correspondente a $15,5 \%$, estendendo-se por todo o município e com maiores constatações na região norte, sudeste e sul. Uma característica importante para se destacar na imagem é a presença de ruídos em forma de nuvens, que correlacionado aos corpos d'agua são identificados por pontos vermelhos específicos na imagem, caracterizando a classe 1 (-0,61 e 0$)$ representando $1,0 \%$ da área constatada pela imagem.

A imagem 2 (figura 01) também corresponde ao ano de 2001, porém ao mês de setembro equivalente a um período seco. Em toda área representada, a grande predominância da classe $2(0$ a 0,15$)$ com $31 \%$ e $3(0,15$ a 0,3$) 55 \%$ é destacável, caracterizando a pouca densidade de biomassa verde pelo o município, concentrando-se nas porções norte, leste, sul e oeste-nordeste. Já as maiores densidades de biomassa estão localizados em pontos específicos e quase isolados, com maior predominância na região sudeste que apresenta a classe $5(0,4$ a $0,74) 6 \%$ e em maior influência a classe $4(0,3$ a 0,4$) 6,8 \%$.

Já a imagem 3 (figura 2) foi obtida em 2014 e corresponde ao mês de Maio, período chuvoso. É possível perceber que a região norte apresenta maior densidade de biomassa, com predominância da classe $4(0,3$ a 0,4$)$ que representa $41,8 \%$ do município e a classe $5(0,4$ a $0,63)$ com $5,3 \%$, diferente da imagem 2 e 3 que apontou a maior densidade a região sudeste. As áreas que representam as menores concentrações de biomassa, apresentam-se principalmente pela classe $3(0,15$ a 0,3$)$ com $49,8 \%$ do município e a classe $2(0$ a 0,15$)$ apresentando $2,5 \%$ com pouco destaque na imagem. 
Na imagem 4 (figura 02) gerada em Setembro de 2016 é claramente visível a baixa concentração da biomassa verde, conceituada pela classe $2(0$ a 0,15$)$ com cerca de 32,8\% e em maior quantidade a classe $3(0,15$ a 3$)$ com $64 \%$ do município. Quase não há grandes concentrações de biomassa na imagem, destacando-se apenas em uma pequena facha na região sudeste e espaços espalhados pelo município classificado pela classe $4(0,3$ a 0,4$)$ com 2,3\% da área, ou seja, em pouquíssimas extensões.

\section{CONSIDERAÇÕES FINAIS}

Deve-se levar em consideração dois setores constados em todas as imagens analisadas. A primeira refere-se à facha verde localizada na região nordeste do município, que corresponde a uma área destinada à agricultura irrigada, apresentando intensa cor verde em todas as imagens analisadas, independente das condições climáticas. A segunda é referente à forte cor vermelha representada pelo lago do município, ao lado da área destinada a agricultura irrigada, localizada na porção centro-norte do município, que possui tal coloração devido a não absorção da água a banda do infravermelho presente na formula do NDVI.

A vulnerabilidade da região ao processo de desertificação se caracteriza ainda mais com a desnudez do solo, que além de contar com as características ambientais, como: irregularidade climática e fisionomia as vegetação típica, a ação da sociedade tem sido cada vez mais devastadora. As variações na densidade da biomassa verde no município nos diferentes anos, sobressaem diante da sazonalidade climática e do uso ambiental da terra. É claramente perceptível que as imagens do período chuvoso (1 e 3), apresentam maior densidade de biomassa, contrário as imagens ( 2 e 4) referentes ao mês seco com baixas concentração de biomassa, em que se destacam as classes com baixas a nenhuma cobertura vegetal. A região que apresentou maior concentração de biomassa verde nas imagens é a sudeste, onde se encontra a maior densidade vegetacional do munícipio, sem características urbanas e desenvolvimento de atividades agropecuárias. Porém, há variações e exceções, como a imagem 3 que constatou a região norte como maior densidade de biomassa. As demais áreas do município apresentaram baixa concentração de biomassa em todas as imagens, destacam-se, sobretudo a poção a porção leste, centro, sul e em algumas imagens, a região norte. Contudo, é possível afirmar que o desmatamento típico gera desnudez do solo tornando-o improdutivo, expondo a processos erosivos, aumento da temperatura da sua superfície pela exposição direta aos raios solares, aumento do albedo e entre outras várias consequências que justificam a importância do estudo da biomassa verde e seu comportamento.

\section{REFERÊNCIAS}

AB'SABER, Aziz Nacib. Sertões e sertanejos: uma Geografia humana sofrida. In.: Estudos Avançados: Dossiê Nordeste seco. USP, v.13. n 36 - maio/ agosto. 1999 - ISSN 0103-4014.

BRASIL, Ministério do Meio Ambiente. Programa Nacional de Combate à Desertificação e Mitigação dos Efeitos da Seca - PAN-Brasil. Brasília, DF: Ministério do Meio Ambiente; Secretaria de Recursos Hídricos, 2004.

HARE, F. WARREN A. et al. Desertificação: causas e consequências. Lisboa: Fundação Calauste Gulbenkian, 1992. 678p.

LOBAO, J. S. B.; SILVA, B.C.M.N. Análise socioambiental na região semiárida da Bahia: geoprocessamento com subsidio ao ordenamento territorial. Feira de Santana: UEFS, 2013, 353p.

MATALLO JR., Heitor. Indicadores de desertificação: histórico e perspectivas. Cadernos da UNESCOBrasil, série Meio Ambiente e Desenvolvimento, v. 2. Brasília: Unesco, 2001. VASCONCELOS SOBRINHO, J. "Núcleos de Desertificação no Polígono das 67 Secas". In: Anais do ICB 1.Universidade Federal de Pernambuco: Recife, 1971. 